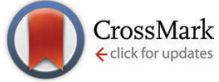

Cite this: Phys. Chem. Chem. Phys., 2014, 16, 21717

Received 19th July 2014, Accepted 22nd August 2014

DOI: $10.1039 / c 4 c p 03199 g$

www.rsc.org/pccp

\title{
A face-sharing bi-icosahedral model for $\mathrm{Al}_{23}{ }^{-} \dagger$
}

\section{K. Koyasu ${ }^{a b}$ and T. Tsukuda*ab}

A face-sharing bi-icosahedral motif is proposed as a candidate structure of the magic cluster, $\mathrm{Al}_{23}{ }^{-}$, on the basis of DFT calculations. The structure can be viewed as a quasi-molecule made of two $\operatorname{Al}_{13}\left(D_{3 d}\right)$ superatoms with an open electronic configuration via constructive overlap of $1 \mathrm{~F}$ and $2 \mathrm{P}$ superatomic orbitals. A face-sharing tri-icosahedral motif is also predicted for $\mathrm{Al}_{33}{ }^{-}$

\section{Introduction}

A cluster of simple metals can be viewed as a "superatom" since valence electrons confined in a jellium-like potential field are accommodated in a series of quantized orbitals. These superatomic orbitals (SAOs) are named 1S, 1P, 1D, 2S, 1F, 2P, 1G, 2D, 3S, 1H, 1I, etc., in order of energy, where S, P, D, F, G, H, and I represent the angular momenta, $L=0,1,2,3,4,5$, and 6 , respectively. ${ }^{1}$ The superatom concept has been verified experimentally and successfully used to explain the magic numbers of clusters of s-electron (ref. 1) metals, such as $\mathrm{Na}$ (ref. 2) and $\mathrm{Au},{ }^{3,4}$ and trivalent $\mathrm{Al} .{ }^{5}$ For example, the well-known magic cluster, $\mathrm{Al}_{13}{ }^{-}$, can be viewed as a superatom with an icosahedral motif and a closed electronic shell with 40 valence electrons. ${ }^{5}$ With the prospect that superatoms will serve as the building blocks of novel nanomaterials, considerable effort has been made to develop Au superatoms protected by ligands, such as thiolates (RS) and phosphines $\left(\mathrm{PR}_{3}\right)^{6,7}$ For example, $\mathrm{Au}_{11}{ }^{3+}(8 \mathrm{e})^{8,9}$ and $\mathrm{Au}_{13}{ }^{5+}(8 \mathrm{e})^{10-13}$ superatoms protected by ligands have been isolated. Their high stability has been explained by an extended version of the superatomic concept that takes into account electron transfer from the Au cores to the ligands. ${ }^{14}$

An interesting challenge is to construct a new class of pseudomolecules from superatoms (superatomic molecules) by their direct connection or partial fusion..$^{15}$ So far, three types of ligand-protected $\mathrm{Au}$ superatomic molecules with bi-icosahedral motifs have been synthesized (Chart 1). The $\mathrm{Au}_{25}{ }^{9+}(16 \mathrm{e})$ core of $\left[\mathrm{Au}_{25}(\mathrm{SR})_{5}\left(\mathrm{PR}_{3}^{\prime}\right)_{10} \mathrm{Cl}_{2}\right]^{2+}$ comprises two $\mathrm{Au}_{13}{ }^{5+}(8 \mathrm{e})$ superatoms with the closed electronic

\footnotetext{
${ }^{a}$ Department of Chemistry, School of Science, The University of Tokyo, 7-3-1 Hongo, Bunkyo-ku, Tokyo 113-o033, Japan. E-mail: tsukuda@chem.s.u-tokyo.ac.jp

${ }^{b}$ Elements Strategy Initiative for Catalysts and Batteries (ESICB), Kyoto University, Katsura, Kyoto 615-8520, Japan

† Electronic supplementary information (ESI) available: Full citation of ref. 31, full list of atomic coordinates and orbital energy levels with SAOs of the three isomers of $\mathrm{Al}_{23}{ }^{-}$and $\mathrm{Al}_{33}{ }^{-}$, and the energy diagram with SAOs of distorted $\mathrm{Al}_{13}{ }^{-}$. See DOI: $10.1039 / \mathrm{c} 4 \mathrm{cp} 03199 \mathrm{~g}$
}

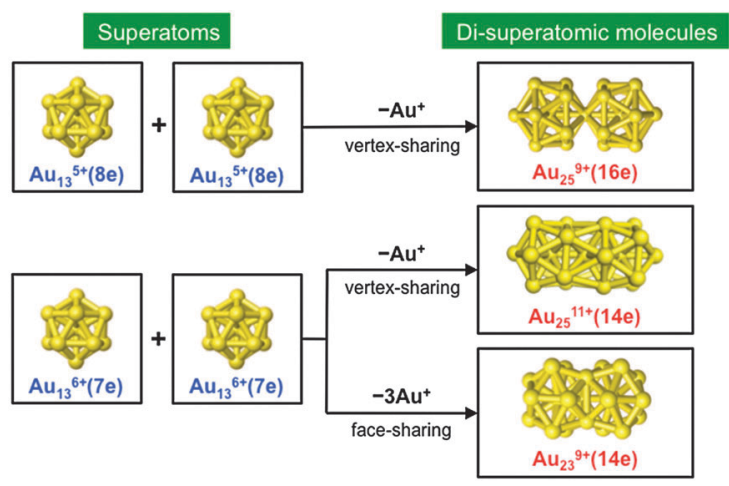

Chart 1 Examples of Au superatomic molecules.

configuration $(1 \mathrm{~S})^{2}(1 \mathrm{P})^{6}$ by sharing a vertex atom. ${ }^{16}$ The $\mathrm{Au}_{23}{ }^{9+}(14 \mathrm{e})$ core of $\mathrm{Au}_{38}(\mathrm{SR})_{24}$ (ref. 17) and the $\mathrm{Au}_{25}{ }^{11+}(14 \mathrm{e})$ core of $\mathrm{Au}_{25}(\mathrm{SR})_{11}$ (ref. 18) are constructed from two $\mathrm{Au}_{13}{ }^{6+}(7 \mathrm{e})$ superatoms with an open electronic configuration of $(1 \mathrm{~S})^{2}(1 \mathrm{P})^{5}$ by sharing a facet and vertex, respectively. Yang and Cheng developed the super valence bond (SVB) model to explain the bonding of two superatoms in $\mathrm{Au}_{23}{ }^{9+}(14 \mathrm{e})$ and found similarities with the bonding in $\mathrm{F}_{2} \cdot{ }^{19,20}$ The production of poly- $\mathrm{Au}_{13}$ icosahedra with different bonding schemes has been theoretically proposed..$^{21,22}$

In contrast, $\mathrm{Al}_{13}$-based superatomic molecules corresponding to those in Chart 1 have not been synthesized so far, although mass spectrometry has demonstrated the formation of a variety of superatomic complexes, including $\mathrm{Al}_{13} \mathrm{Na}^{23}{ }^{23} \mathrm{Al}_{13} \mathrm{I}^{-},{ }^{24} \mathrm{Al}_{13} \mathrm{X}(\mathrm{X}=\mathrm{H}, \mathrm{Au}$, and alkali metals $),{ }^{25} \mathrm{Al}_{13}(\mathrm{OAl})_{n},{ }^{26} \mathrm{Cs}^{+} \mathrm{B} @ \mathrm{Al}_{12}{ }^{-}$, and $\mathrm{F}^{-} \mathrm{P} @ \mathrm{Al}_{12}{ }^{+} \cdot{ }^{+27}$ Assemblies of endohedral Al clusters, $\mathrm{X} @ \mathrm{Al}_{12}-\mathrm{Y} @ \mathrm{Al}_{12}(\mathrm{X}-\mathrm{Y}=\mathrm{Si}-\mathrm{Si}$, $\mathrm{B}-\mathrm{P}, \mathrm{Al}-\mathrm{P}$ ), were predicted theoretically. ${ }^{28}$ The present work is focused on the structure of one of the magic clusters $\mathrm{Al}_{23}{ }^{-}$, which also exhibits high stability towards $\mathrm{O}_{2}$ like $\mathrm{Al}_{13}{ }^{-5}$. Previous experimental and theoretical studies have proposed that $\mathrm{Al}_{23}{ }^{-}$ has an octupolar-deformed shape (structure 2 in Fig. 1$)^{29,30}$ and 


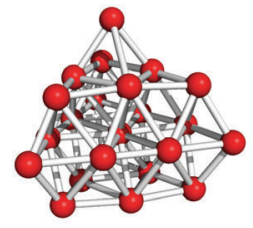

1

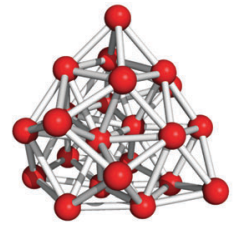

2

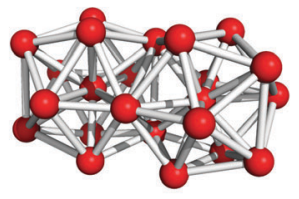

3
Fig. 1 Optimized structures of $\mathrm{Al}_{23}{ }^{-}$

a closed electronic configuration. We propose using DFT calculations the possibility of a face-sharing bi-icosahedral motif for $\mathrm{Al}_{23}{ }^{-}$and the generalized bonding scheme of multiple $\mathrm{Al}_{13}$ units based on the structure of $\mathrm{Al}_{23}{ }^{-}$.

\section{Calculation procedure}

The fully optimized structures, formation energies, and SAO structures of face-sharing bi-icosahedral $\mathrm{Al}_{23}{ }^{-}$and tri-icosahedral $\mathrm{Al}_{33}{ }^{-}$ were obtained at the B3LYP/6-311 $+\mathrm{G}^{* *}$ level using the Gaussian09 package. ${ }^{31}$ As references, we also optimized the structures of $\mathrm{Al}_{23}{ }^{-}$ with deformed octupolar ${ }^{29}$ and fcc-based motifs ${ }^{30}$ and $\mathrm{Al}_{13}{ }^{-}$with the icosahedral $\left(I_{h}\right)$ motif. Frequency analysis of the obtained structures showed no imaginary values indicating that they are local minima in energy. The SAOs were visualized by using the Gaussview program with the isovalue of 0.020 , otherwise noted. The nature of SAOs of the $\mathrm{Al}_{13}{ }^{-}\left(D_{3 \mathrm{~d}}\right)$ moiety of bi-icosahedral $\mathrm{Al}_{23}{ }^{-}$(3) was studied by monitoring how the energies of the SAOs were changed during the optimization to $\mathrm{Al}_{13}{ }^{-}\left(I_{\mathrm{h}}\right)$.

\section{Results and discussion}

Fig. 1 shows the geometries of three optimized $\mathrm{Al}_{23}{ }^{-}$structures (1-3) in the singlet electronic state. Vibrational analysis confirmed that the geometries are local minima. The atomic coordinates of 1-3 are given in Tables S1-S3 (ESI $\dagger$ ), respectively. Structures 1 and 2 are similar to structures reported previously. ${ }^{29,30}$ Newly-found structure 3 retains a face-sharing bi-icosahedral motif. Fig. 2 shows the structure of 3 in the third angle projection and the optimized structure of $\mathrm{Al}_{13}{ }^{-}\left(I_{\mathrm{h}}\right)$. The average $\mathrm{Al}-\mathrm{Al}$ bond lengths at the joint (3.44 $\AA$ ) and the facets at both ends (3.17 $\AA$ ) are significantly elongated compared with that $(2.82 \AA)$ of $\mathrm{Al}_{13}{ }^{-}\left(I_{\mathrm{h}}\right)$. The symmetry of the $\mathrm{Al}_{13}$ moiety of 3 was reduced to $D_{3 \mathrm{~d}}$.

Table 1 compares the relative stability of 1-3. Structures 1 and 2 have comparable stability, ${ }^{29}$ whereas structure $\mathbf{3}$ is less stable than 1 and 2 by $0.97 \mathrm{eV}$. Nevertheless, we cannot exclude the possibility that structure 3 is produced under certain experimental conditions given that structure $\mathbf{3}$ is isolated from $\mathbf{1}$ and $\mathbf{2}$ by significant energy barriers. Table 1 also lists the vertical detachment energy (VDE), which is defined as the energy difference between the neutral and anionic states at the optimized structures of the anion. The VDE values of 1-3 are comparable to the experimental value $(3.57 \mathrm{eV}) .^{29}$

Energy diagrams of SAOs of 1-3 are shown in Fig. 3. Large HOMO-LUMO gaps for all the structures (Table 1) indicate that their high stability originates from their closed electronic shells.
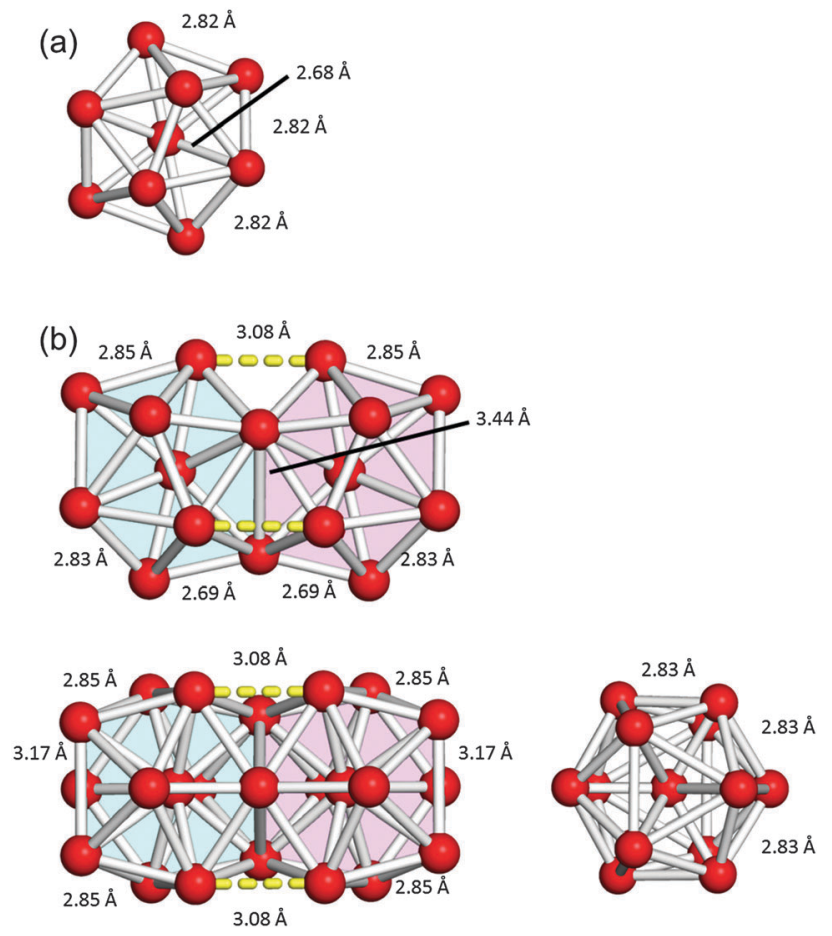

Fig. 2 The structures of (a) $\mathrm{Al}_{13}{ }^{-}\left(I_{\mathrm{h}}\right)$ and (b) $\mathrm{Al}_{23}{ }^{-}$(3) in the third angle projection. Three bonds between the two $\mathrm{Al}_{13}$ units in 3 are shown by yellow dashed lines.

Table 1 Relative stability, vertical detachment energy, and the HOMOLUMO gap of $\mathrm{Al}_{23}{ }^{-}(\mathbf{1 - 3})$

\begin{tabular}{llll}
\hline Structure & $\mathbf{1}$ & $\mathbf{2}$ & $\mathbf{3}$ \\
\hline$\Delta E(\mathrm{eV})$ & 0.00 & 0.05 & 0.97 \\
${\mathrm{VDE}(\mathrm{eV})^{a}}^{\mathrm{HOMO}-\text { LUMO gap }(\mathrm{eV})}$ & 3.16 & 3.28 & 3.17 \\
${ }^{a}$ Experimental value: $3.57 \mathrm{eV}$ (ref. 29$)$. & 1.63 & 1.83 & 1.55 \\
\hline
\end{tabular}

The electronic structures of $\mathbf{1}$ and $\mathbf{2}$ are similar and the energy diagrams of $\mathbf{1}$ and $\mathbf{2}$ indicate that they can be viewed as superatoms with nearly spherical morphologies and a closed electronic configuration of $(1 \mathrm{~S})^{2}(1 \mathrm{P})^{6}(1 \mathrm{D})^{10}(2 \mathrm{~S})^{2}(1 \mathrm{~F})^{14}(2 \mathrm{P})^{6}(1 \mathrm{G})^{18}(2 \mathrm{D})^{10}(3 \mathrm{~S})^{2}$. In contrast, the electronic structure of $\mathbf{3}$ is significantly different from those of $\mathbf{1}$ and 2. The occupied SAOs of 3 are named \#116-\#150 in order of energy (Fig. 3) and their shapes are visualized in Fig. S1 and S2 (ESI $\dagger$ ). In the following, we attempt to interpret the electronic structure of 3 in the framework of the SVB model ${ }^{19}$ rather than that of a deformed (elongated) superatom. According to the SVB model, ${ }^{19}$ the face-sharing bi-icosahedral $\mathrm{Al}_{23}{ }^{-}$(3) is constructed from two $\mathrm{Al}_{13}{ }^{4+}(35 \mathrm{e})$ superatoms with an open electronic configuration,

$$
\mathrm{Al}_{23}{ }^{-}(70 \mathrm{e})=2 \times \mathrm{Al}_{13}{ }^{4+}(35 \mathrm{e})-3 \mathrm{Al}^{3+} .
$$

The physical meaning of removing $3 \mathrm{Al}^{3+}$ nuclei is the reduction of the electron confinement volume. To gain an insight into the bonding scheme between two $\mathrm{Al}_{13}{ }^{4+}$ superatoms in $\mathrm{Al}_{23}{ }^{-}$(3), we consider how the SAOs of 3 are constructed from those of $\mathrm{Al}_{13}{ }^{4+}$ by comparing their shapes. In the following, $\mathrm{Al}_{13}{ }^{-}$with the same geometry $\left(D_{3 \mathrm{~d}}\right)$ as $\mathrm{Al}_{23}{ }^{-}$(3) was considered as the building unit, 


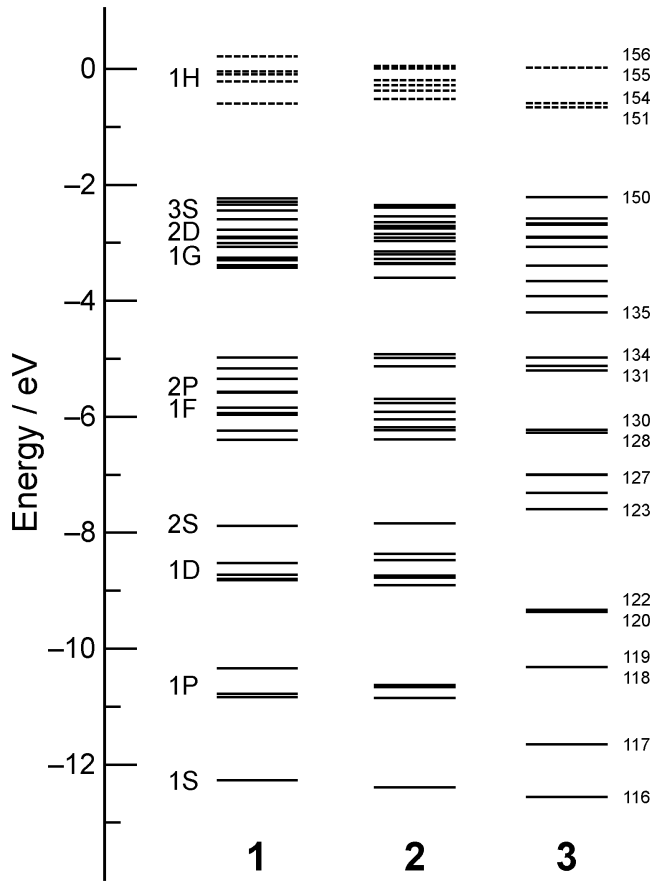

Fig. 3 Energy diagram of SAOs of $\mathbf{1 - 3}$. The solid and dotted lines represent occupied and unoccupied orbitals, respectively.

instead of $\mathrm{Al}_{13}{ }^{4+}$. The nature of the SAOs of $\mathrm{Al}_{13}{ }^{-}\left(D_{3 \mathrm{~d}}\right)$ was characterized by correlation with those of $\mathrm{Al}_{13}{ }^{-}\left(I_{\mathrm{h}}\right)$ (Fig. S3, ESI $\dagger$ ), which was established by following the evolution of the SAOs over the course of structural optimization from $\mathrm{Al}_{13}{ }^{-}\left(D_{3 \mathrm{~d}}\right)$ to $\mathrm{Al}_{13}{ }^{-}\left(I_{\mathrm{h}}\right)$ (Fig. S4-S6, ESI $\dagger$ ).

The correlation between the SAOs of $3(\# 116-\# 150)$ and those of $\mathrm{Al}_{13}{ }^{-}\left(D_{3 \mathrm{~d}}\right)$ is summarized in Table 2 . The construction of the low-lying SAOs (Fig. S1, ESI $\dagger$ ) is straightforward. For example, SAOs \#116 and \#117 are assigned to bonding and antibonding orbitals, respectively, constructed by interactions of SAO \#66 of $\mathrm{Al}_{13}{ }^{-}$with $1 \mathrm{~S}$ nature (Table 2 and Fig. S3, ESI $\dagger$ ). SAOs

Table 2 Correlation of SAOs of $\mathrm{Al}_{23}{ }^{-}$(3) and SAO of $\mathrm{Al}_{13}{ }^{-}\left(D_{3 \mathrm{~d}}\right)$

\begin{tabular}{lll}
\hline SAO of $\mathrm{Al}_{23}{ }^{-}(3)^{a}$ & & \\
\cline { 1 - 2 } Bonding & Anti-bonding & \\
\hline $116(1 \Sigma)$ & $117(2 \Sigma)$ & $66(1 \mathrm{~S})$ \\
$118,119(1 \Pi)$ & $121,122(2 \Pi)$ & $67,68\left(1 \mathrm{P}_{x, y}\right)$ \\
$120(3 \Sigma)$ & $123(4 \Sigma)$ & $69\left(1 \mathrm{P}_{z}\right)$ \\
$124,125(1 \Delta)$ & $128,129(2 \Delta)$ & $70,71(1 \mathrm{D})$ \\
$126,127(3 \Pi)$ & $132,133(4 \Pi)$ & $72,73(1 \mathrm{D})$ \\
$130(5 \Sigma)$ & $131(6 \Sigma)$ & $74(2 \mathrm{~S})$ \\
$134(7 \Sigma)$ & $143(9 \Sigma)$ & $75\left(1 \mathrm{D}_{z}\right)$ \\
$136,137(3 \Delta)$ & $149,150(4 \Delta)$ & $76,77(1 \mathrm{~F})$ \\
$135(1 \Phi)$ & $141(3 \Phi)$ & $78(1 \mathrm{~F})$ \\
$138(2 \Phi)$ & $144(4 \Phi)$ & $79(1 \mathrm{~F})$ \\
$139,140(5 \Pi)$ & $147,148(7 \Pi)$ & $80,81\left(2 \mathrm{P}_{x, y}\right)$ \\
$145,146(6 \Pi)$ & {$[155,156](8 \Pi)$} & $82,83(1 \mathrm{~F})$ \\
$142(8 \Sigma)$ & {$[151]^{b}(10 \Sigma)$} & $84\left(2 \mathrm{P}_{z}\right)$
\end{tabular}

${ }^{a}$ The SAOs in brackets are unoccupied orbitals. The notations in parentheses $(1 \Sigma, 2 \Sigma, \ldots)$ indicate orbital symmetries numbered in the order of energy in the same symmetry. ${ }^{b}$ LUMO of $\mathrm{Al}_{23}{ }^{-}$(3). ${ }^{c}$ The orbital symmetries shown in parentheses are those of the corresponding SAOs of $\mathrm{Al}_{13}{ }^{-}\left(I_{h}\right)$ (Fig. S3, ESI).
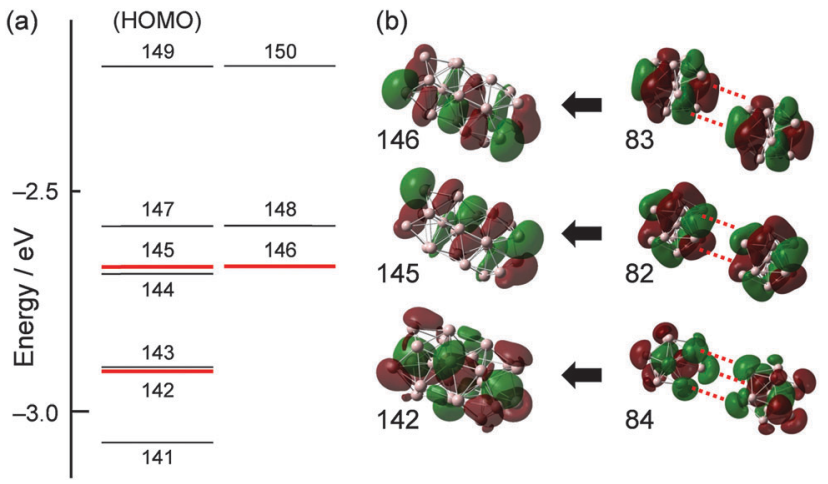

Fig. 4 (a) Energy diagram of $\mathrm{SAOs}_{\text {of }} \mathrm{Al}_{23}{ }^{-}$(3). (b) Schematic representation of the bonding interaction between two SAOs of $\mathrm{Al}_{13}{ }^{-}\left(D_{3 \mathrm{~d}}\right)$.

\#118-\#134 and \#143 are constructed from the SAO of $\mathrm{Al}_{13}{ }^{-}$with $1 \mathrm{P}$, $1 \mathrm{D}$, and 2S nature. The high-lying SAOs \#135-\#150 except \#143 (Fig. $\mathrm{S} 2, \mathrm{ESI} \dagger$ ) are made from the SAOs of $\mathrm{Al}_{13}{ }^{-}$with $1 \mathrm{~F}$ and $2 \mathrm{P}$ nature (Table 2 and Fig. S3, ESI $\dagger$ ). In 3, SAOs \#142, \#145, and \#146 with bonding nature are occupied whereas their anti-bonding counterparts \#151, \#155, and \#156 are unoccupied (Table 2). The occupation of SAOs \#142, \#145, and \#146 is responsible for the bonding interaction between the two $\mathrm{Al}_{13}$ superatoms. SAOs \#142, \#145, and $\# 146$ are constructed from the SAO of $\mathrm{Al}_{13}{ }^{-}$with $2 \mathrm{P}, 1 \mathrm{~F}$, and $1 \mathrm{~F}$ nature, respectively, as shown in Fig. 4. The bond order (BO) for $\mathrm{Al}_{23}{ }^{-}$(3) is estimated to be 3 according to the definition in conventional $\mathrm{VB}$ theory. Note that the $\mathrm{BO}$ value for $\mathrm{Al}_{23}{ }^{-}$(3) is larger than that $(\mathrm{BO}=1)$ of $\mathrm{Au}_{23}{ }^{9+}$ (Chart 1$)$.

We can rewrite eqn (1) as follows by considering $\mathrm{Al}_{13}{ }^{-}(40 \mathrm{e})$ as a superatomic unit,

$\mathrm{Al}_{23}{ }^{-}(70 \mathrm{e})=\left[2 \times \mathrm{Al}_{13}{ }^{-}(40 \mathrm{e})-3 \mathrm{Al}^{3+}\right]-10 \mathrm{e}=\mathrm{Al}_{23}{ }^{11-}(80 \mathrm{e})-10 \mathrm{e}$.

This indicates that two $\mathrm{Al}_{13}{ }^{-}$(40e) superatoms are bonded by sharing 10 electrons for each superatomic bond. Counterintuitively, the $\mathrm{BO}$ of $\mathrm{Al}_{23}{ }^{-}$(3) is not 5, but 3. This suggests that 8 and 2 electrons are removed from anti-bonding and bonding orbitals of a putative $\mathrm{Al}_{23}{ }^{11-}(80 \mathrm{e})$, respectively. By extending this idea, we can predict a series of sizes for the linear polymers of $\mathrm{Al}_{13}(40 \mathrm{e})$ which are connected by sharing the facet as follows,

$$
\begin{aligned}
& \mathrm{Al}_{33}{ }^{-}(100 \mathrm{e})=3 \times \mathrm{Al}_{13}{ }^{-}(40 \mathrm{e})-2 \times 3 \mathrm{Al}^{3+}-2 \times 10 \mathrm{e} \\
& \mathrm{Al}_{43}{ }^{-}(130 \mathrm{e})=4 \times \mathrm{Al}_{13}{ }^{-}(40 \mathrm{e})-3 \times 3 \mathrm{Al}^{3+}-3 \times 10 \mathrm{e}
\end{aligned}
$$

Interestingly, it was reported that $\mathrm{Al}_{33}{ }^{-}$is stable against etching by $\mathrm{O}_{2}{ }^{32}$ The stability of $\mathrm{Al}_{33}{ }^{-}$(100e) cannot be explained by the number of effective valence electrons since superatomic shell closure under spherical potential is accomplished at $n^{*}=$ 92 and 106. Thus, formation of a linear trimer is a possible explanation for the chemical stability of $\mathrm{Al}_{33}{ }^{-}$. To test this hypothesis, we conducted structural optimization of $\mathrm{Al}_{33}{ }^{-}$with a tri-icosahedral motif. We obtained a local minimum structure as shown in Fig. 5. The atomic coordinates of the optimized $\mathrm{Al}_{33}{ }^{-}$are given in Table $\mathrm{S} 4(\mathrm{ESI} \dagger)$. 

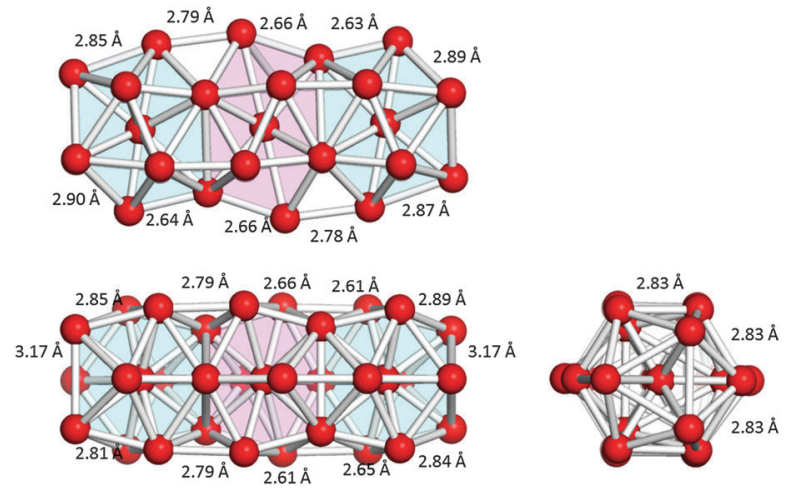

Fig. 5 Optimized structure of tri-icosahedral $\mathrm{Al}_{33}{ }^{-}$in the third angle projection.

\section{Conclusions}

DFT calculations allowed us to propose face-sharing bi- and triicosahedral motifs as possible structures of the magic clusters, $\mathrm{Al}_{23}{ }^{-}$and $\mathrm{Al}_{33}{ }^{-}$. Constructive overlap of $1 \mathrm{~F}$ and $2 \mathrm{P}$ superatomic orbitals of deformed $\mathrm{Al}_{13}\left(D_{3 \mathrm{~d}}\right)$ units is responsible for the bonding of two $\mathrm{Al}_{13}$ superatoms. Fabrication of these unique Al clusters is a future challenge required to establish this building-up principle and to develop new functional materials with a ubiquitous element.

\section{Acknowledgements}

This research was financially supported by the Funding Program for Next Generation World-Leading Researchers (NEXT Program) (GR-003), the "Elements Strategy Initiative for Catalysts \& Batteries (ESICB)," supported by the Ministry of Education, Culture, Sports, Science and Technology (MEXT), Japan. We thank Dr Hironori Tsunoyama (Keio Univ.) and Ms Tomomi Watanabe (The Univ. of Tokyo) for their contribution at the initial stage of this research.

\section{Notes and references}

1 W. A. de Heer, Rev. Mod. Phys., 1993, 65, 611.

2 W. D. Knight, K. Clemenger, W. A. de Heer, W. A. Saunders,

M. Y. Chou and M. L. Cohen, Phys. Rev. Lett., 1984, 52, 2141.

3 K. J. Taylor, C. L. Pettiette-Hall, O. Cheshnovsky and

R. E. Smalley, J. Chem. Phys., 1992, 96, 3319.

4 L.-M. Wang and L.-S. Wang, Nanoscale, 2012, 4, 4038.

5 R. E. Leuchtner, A. C. Harms and A. W. Castleman, Jr., J. Chem. Phys., 1989, 91, 2753.

6 R. Jin, Nanoscale, 2010, 2, 343.
7 P. Maity, S. Xie, M. Yamauchi and T. Tsukuda, Nanoscale, 2012, 4, 4027.

8 Y. Yanagimoto, Y. Negishi, H. Fujihara and T. Tsukuda, J. Phys. Chem. B, 2006, 110, 11611.

9 B. S. Gutrath, U. Englert, Y. Wang and U. Simon, Eur. J. Inorg. Chem., 2013, 2002.

10 C. E. Briant, B. R. C. Theobald, J. W. White, L. K. Bell, D. M. P. Mingos and A. J. Welch, J. Chem. Soc., Chem. Commun., 1981, 201.

11 M. W. Heaven, A. Dass, P. S. White, K. M. Holt and R. W. Murray, J. Am. Chem. Soc., 2008, 130, 3754.

12 M. C. Zhu, M. Aikens, F. J. Hollander, G. C. Schatz and R. Jin, J. Am. Chem. Soc., 2008, 130, 5883.

13 Y. Shichibu and K. Konishi, Small, 2010, 6, 1216.

14 M. Walter, J. Akola, O. Lopez-Acevedo, P. D. Jadzinsky, G. Calero, C. J. Ackerson, R. L. Whetten, H. Grönbeck and H. Häkkinen, Proc. Natl. Acad. Sci. U. S. A., 2008, 105, 9157.

15 J. Nishigaki, K. Koyasu and T. Tsukuda, Chem. Rec., DOI: 10.1002/tcr.201402011, in press.

16 Y. Shichibu, Y. Negishi, T. Watanabe, N. K. Chaki, H. Kawaguchi and T. Tsukuda, J. Phys. Chem. C, 2007, 111, 7845.

17 H. Qian, W. T. Eckenhoff, Y. Zhu, T. Pintauer and R. Jin, J. Am. Chem. Soc., 2010, 132, 8280.

18 J. Nishigaki, S. Yamazoe, S. Kohara, A. Fujiwara, W. Kurashige, Y. Negishi and T. Tsukuda, Chem. Commun., 2014, 50, 839.

19 L. Cheng, C. Ren, J. Zhang and X. Yang, Nanoscale, 2013, 5, 1475.

20 Y. Yuan, L. Cheng and J. Yang, J. Phys. Chem. C, 2013, 117, 13276.

21 K. Nobusada and T. Iwasa, J. Phys. Chem. C, 2007, 111, 14279.

22 D. Jiang, K. Nobusada, W. Luo and R. L. Whetten, ACS Nano, 2009, 3, 2351.

23 A. Nakajima, K. Hoshino, T. Naganuma, Y. Sone and K. Kaya, J. Chem. Phys., 1991, 95, 7061.

24 D. E. Bergeron, P. J. Roach, A. W. Castleman, Jr., N. O. Jones and S. N. Khanna, Science, 2005, 307, 231.

25 Y. J. Ko, A. Shakya, H. Wang, A. Grubisic, W. Zheng, M. Götz, G. Ganteför, K. H. Bowen, P. Jena and B. Kiran, J. Chem. Phys., 2010, 133, 124308.

26 T. Watanabe and T. Tsukuda, J. Phys. Chem. C, 2013, 117, 6664. 27 M. Akutsu, K. Koyasu, J. Atobe, N. Hosoya, K. Miyajima, M. Mitsui and A. Nakajima, J. Phys. Chem. A, 2006, 110, 12073. 28 T. Iwasa and A. Nakajima, J. Phys. Chem. C, 2013, 117, 21551. 29 J. Akola, M. Manninen, H. Häkkinen, U. Landman, X. Li and L.-S. Wang, Phys. Rev. B, 2000, 62, 13216.

30 A. Aguado and J. M. López, J. Chem. Phys., 2009, 130, 064704. 31 M. J. Frisch, et al., Gaussian 09, Revision C.01, (see ESI $\dagger$ for full citation).

32 R. L. Hettich, J. Am. Chem. Soc., 1989, 111, 8582. 